\title{
VALEUR ALIMENTAIRE DE FARINES SOLUBLES DE POISSON BLANC PRÉPARÉES SELON DIVERS PROCÉDÉS TECHNOLOGIQUES : ESSAIS D'INCORPORATION AUX ALIMENTS D'ALLAITEMENT ARTIFICIEL DU PORGELET SEVRÉ A 12 JOURS
}

\author{
B. SEVE. A. AUMAITRE et P. TORD* \\ Station de Recherches sur l'Elevage des porcs, \\ Centre national de Recherches zootechniques, I. N.R. A., \\ 78350 Jouy en Josas \\ * Coopérative de Traitement des Produits de la Pêche, \\ 62480 Le Portel
}

\section{RÉSUMÉ}

Au cours de deux expériences sur I 56 porcelets sevrés à I 2 jours, on a mesuré la valeur alimentaire de concentrés de protéines préparés par hydrolyse enzymatique du poisson frais. A la suite d'un test préliminaire sur rats, deux produits (farines solubles 80 et 9o) sont retenus pour cette expérimentation, un troisième (farine soluble 95) étant éliminé en raison d'une détérioration de sa valeur alimentaire consécutive au traitement de délipidation. Les farines solubles remplacent en association avec de la maltodextrine des quantités croissantes $(33,66$ et roo p. roo) de lait écrémé dans les "laits artificiels" granulés distribués aux porcelets jusqu'à l'âge de 35 jours. Les résultats montrent que l'élimination de la fraction la moins soluble de l'hydrolysat, nécessaire à la production de farine 90 , entraîne un abaissement de la valeur nutritive du produit fini. En outre, l'association du concentré de protéines le moins soluble (33 p. roo de protéines de la ration, et du lait écrémé est favorable à la fois au maintien de bonnes performances de croissance du porcelet, d'un état sanitaire satisfaisant et d'une excellente digestibilité apparente des protéines. Cependant, aux taux les plus élevés de substitution du lait écrémé, cette digestibilité de l'azote de la ration $s$ abaisse moins rapidement avec le produit le plus soluble, et ce résultat, en accord avec les observations faites chez le Rat, tend à confirmer l'intérêt du traitement enzymatique du poisson. I] semble donc que la technologie utilisée pour obtenir un produit de solubilité maximum entraîne une diminution de la valeur alimentaire du produit, imputable à l'équilibre des acides aminés de la protéine.

\section{INTRODUCTION}

La composition en acides aminés de la protéine de farine de poisson (PIon et FaUconneau, 1966) explique en grande partie la supériorité de cette source de protéines sur la plupart des aliments azotés d'origine végétale, chez le Porc en crois- 
sance finition (BREIREM, I948; CARPENTER, I95 ; FÉVRIER et al,, I954 ; LAKSESVELA, I96I). L'utilisation de la farine de poisson dans les régimes de sevrage est donc justifiée, compte tenu des exigences plus grandes du porcelet pour la qualité des protéines de son aliment. Cependant, le très jeune porcelet utilise mal la farine de poisson préparée classiquement (Cunningham et Brisson, I957), alors qu'il tolère bien un concentré de protéines de poisson délipidé (POND et al., I97I). Ainsi, les résultats concordants de Combs et al. (I963), KASPAR (I966) et BAYLEY et Holmes (1973) montrent que la digestibilité des protéines des farines de poisson est d'autant plus faible que l'animal est plus jeune; la différence avec les protéines de lait de vache a surtout été soulignée vers 2 à 3 semaines d'âge. Il semble donc que malgré leurs qualités, les protéines de farine de poisson ne sont pas adaptées à l'immaturité de l'équipement protéolytique du jeune porcelet (PEKas, Thompson et Hays, I966 ; Corring et Aumaitre, I97I). De la même façon que pour l'équipement amylolytique, la supplémentation de la ration en enzymes ne parait pas constituer une solution efficace à cette insuffisance (AumaITRE, I97I). La prédigestion enzymatique des protéines alimentaires a fait l'objet d'un nombre limité d'études (Cunningham et BRISSON, I957), en raison surtout de l'obstacle technologique. Elle peut présenter un intérêt dans le cas du poisson à partir duquel on sait maintenant fabriquer des concentrés de protéines solubles $\left(^{1}\right)$. Les variantes du procédé permettent de préparer toute une gamme de produits et, comme le proposent BARRICK, VESTAL et SHrEWSBUR (I943), nous avons pensé utiliser le Rat pour faire un premier choix parmi les différentes préparations. L'objet essentiel de cette étude reste la détermination du taux optimum de concentré de protéines solubles de poisson dans les laits artificiels secs pour porcelets sevrés à 12 jours, en batterie, selon une technique utilisée d'abord par DyRendahL et al. (I958) et plus récemment par VAN DER HEYdE (I969). Le risque sanitaire réduit et la simplicité des manipulations nous font préférer ce système à une technique d'allaitement sous forme liquide qui autoriserait un sevrage plus précoce encore (CATRON et al., I953; BRAUDE et al., I970). Notre première préoccupation sera ici de rechercher les possibilités de remplacement, dans les aliments d'allaitement, des protéines du lait écrémé par ces concentrés de protéines solubles de poisson.

\section{MATÉRIEL ET MÉTHODES}

\section{A. - Les Produits testés}

Les concentrés de protéines solubles de poisson que nous appellerons par la suite farines solubles, sont préparés en pilote industriel à partir de déchets de filetage de poisson blanc (gadidés divers). Leur préparation comporte une étape commune comprenant un broyage, une protéolyse enzymatique $\left(20\right.$ minutes à $70^{\circ} \mathrm{C}$ ) puis l'élimination des parties osseuses par tamisage.

Les traitements subis par la phase liquide et la composition des trois produits obtenus sont rapportés au tableau I. On a fait figurer aussi la composition de la farine de hareng de Norvège utilisée comme témoin lors du test sur le Rat. La teneur en énergie brute de la matière organique traduit la teneur en lipides résiduels des farines. 


\section{TABLEAU I}

Technologie de préparation et analyse des produits soumis aux tests

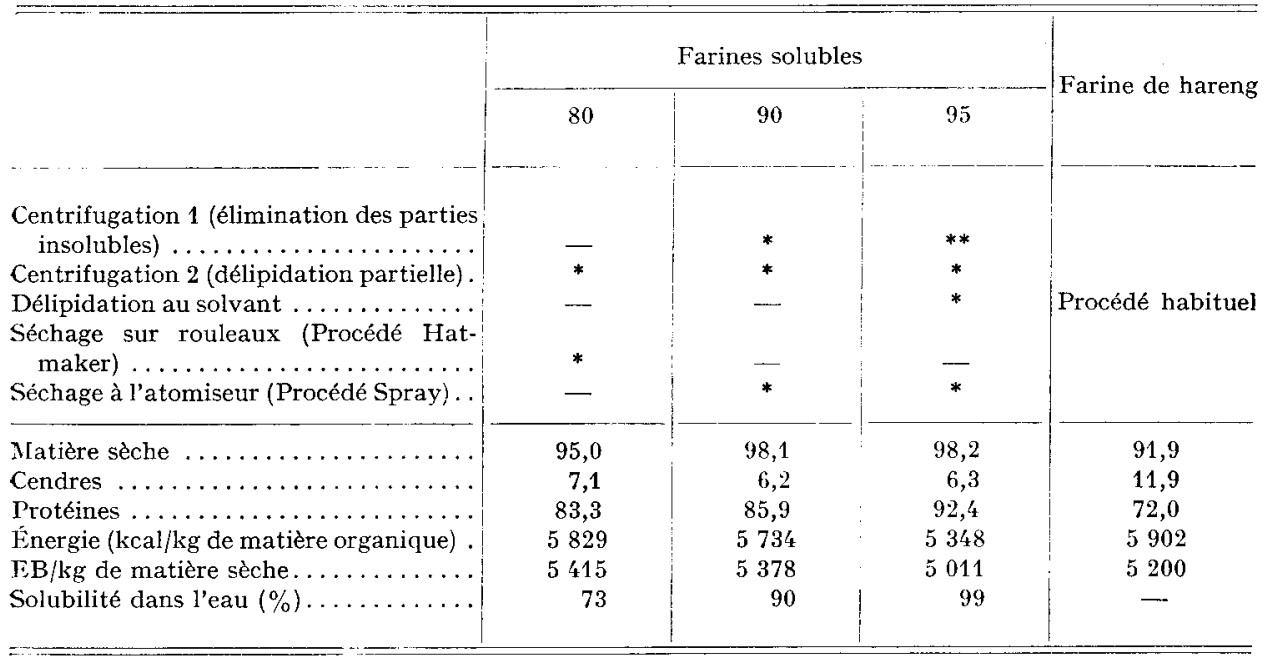

TABLEAU 2

Composition et analyse des régimes de l'expérience sur le Rat (p. 100)

\begin{tabular}{|c|c|c|c|c|c|c|c|c|c|c|}
\hline Source azotée & \multicolumn{3}{|c|}{ Farine soluble 80} & \multicolumn{3}{|c|}{ Farine soluble 90} & \multicolumn{3}{|c|}{ Farine soluble 95} & \multirow{2}{*}{ Témoin } \\
\hline Taux de protéines $(\%)$ & 8 & 10 & 12 & 8 & 10 & 12 & 8 & 10 & 12 & \\
\hline Farine de hareng de & & & & & & & & & & \\
\hline Norvège $\ldots \ldots \ldots \ldots$ & 一 & - & - & - & - & - & - & - & - & 15,1 \\
\hline Farine soluble $80 \ldots \ldots \ldots$ & $9, \overline{5}$ & 11,8 & 14,2 & - & - & - & - & - & - & \\
\hline Farine soluble $90 \ldots \ldots$ & & & & 9,1 & 11,4 & 13,6 & - & - & - & \\
\hline Farine soluble $95 \ldots \ldots$ & & & & & & & 8,3 & 10,4 & 12,5 & \\
\hline Mélange minéral ${ }^{(1)} \ldots \ldots$ & 5,0 & 5,0 & 5,0 & 5,0 & 5,0 & 5,0 & 5,0 & 5,0 & 5,0 & 4,5 \\
\hline Saccharose amidon de maïs & & & & & & & & & & \\
\hline Lipides-cellulose-vitamines & $11,0(2)$ & 11,0 & 11,0 & 11,0 & 11,0 & $\begin{array}{l}11,0 \\
11,0\end{array}$ & 11,0 & $\begin{array}{l}7,0 \\
11,0\end{array}$ & 11,0 & $\begin{array}{l}1,4 \\
11,0\end{array}$ \\
\hline Matière sèche & 95,4 & 95,2 & 95,1 & 95,8 & 95,4 & 95,4 & 95,6 & 95,6 & 95,5 & 94,9 \\
\hline Protéines p. 100 de MS & 7,8 & 10,2 & 12,2 & 8,2 & 10,5 & 12,1 & 8,3 & 10,3 & 12,6 & 11,2 \\
\hline
\end{tabular}

(1) Composition (\%): $\mathrm{Ca}_{2} \mathrm{H}_{2}\left(\mathrm{PO}_{4}\right)_{2}: 37,3 ; \mathrm{KH}_{2} \mathrm{PO}_{4}: 19,8 ; \mathrm{CaCO}_{3}: 26,3 ; \mathrm{NaCl}: 8,80 ; \mathrm{MgCO}_{3}: 6,6$; $\mathrm{FeSO}_{4} 7 \mathrm{H}_{2} \mathrm{O}: 0,66 ; \mathrm{CuSO}_{4} 5 \mathrm{H}_{2} \mathrm{O}: 0,1 ; \mathrm{MnSO}_{4} \mathrm{H}_{2} \mathrm{O}: 0,27 ; \mathrm{ZnSO}_{4}: 0,17 ; \mathrm{Ki}: 0,001 ; \mathrm{K}_{2} \mathrm{SO}_{4}: 0,001$.

$\left({ }^{2}\right)$ Huile d'arachide enrichie en vitamines $A(200 \mathrm{UI} / \mathrm{ml})$ et $\mathrm{D}(40 \mathrm{UI} / \mathrm{ml}): 8$ p. 100 ; cellulose purifiée : 2 p. 100 ; mélange vitaminique : 1 p. 100 comprenant p. 1000 ; vitamine $B_{12}: 0,03$; acide folique : 0,10 ; vit. $\mathrm{K}: 0,50$; thiamine $: 0,80$; acide nicotinique $: 3,0$; pyridoxine $: 0,80$; riboflavine $: 1,50$; acide pantothénique : 3,00 ; inositol : 50,00; acide aminobenzoique : 50,00 ; biotine : 0,02 ; choline : 100,00; amidon q. s. p. : 1000 . 


\section{B. - Expérience sur le Rat}

\section{Schéma expérimental et régimes.}

L'aliment témoin à base de farine de hareng contient i i p. Ioo de protéines. La comparaison des farines solubles se fait à trois taux de protéines 8 , ro et 12 p. Ioo, tous sub-optima pour les besoins du Rat. Cette méthode permet de bien marquer les différences d'efficacité protidique entre les sources de protéines.

La composition des régimes est rapportée au tableau 2. La fraction énergétique comprend de l'huile d'arachide et un mélange glucidique, saccharose et amidon en quantités égales. Les ro aliments sont distribués sous forme sèche pendant 3 semaines, après une semaine de période préexpérimentale avec un régime à base de caséine. Dans tous les régimes, les besoins en minéraux et en vitamines définis par le N. R. C. (I966) pour le Rat sont couverts, par supplémentation à un taux plus élevé du même mélange dans les aliments à base de farines solubles.

\section{Les animaux.}

Les rats de souche $W$ istar $\mathrm{CF}$, sevrés à 2 I jours, sont placés en cage individuelle où ils disposent d'eau à volonté, dans un local climatisé à $22^{\circ}$ et éclairé pendant $\mathbf{2} 2$ heures par jour. A l'issue de la période préexpérimentale, ils sont répartis en ro blocs homogènes de i a animaux, selon leur poids vif et leur gain de poids, et un animal témoin par bloc est abattu après un jeûne de 8 heures. Au cours de la troisième semaine, on collecte individuellement les excrétions fécales sur la moitié de l'effectif. Les carcasses des animaux abattus en fin d'expérience, dans les mêmes conditions que le témoin, sont identifiées, congelées puis conservées à - I $8{ }^{\circ} \mathrm{C}$.

\section{Mesures analyses et expression des résultats.}

On contrôle les quantités consommées et le gain de poids des animaux deux fois par semaine. On calcule l'indice de consommation et le coefficient d'efficacité protidique pour chaque animal.

On détermine sur les fèces lyophilisées puis broyées, les teneurs en matière sèche, cendres et protéines. Connaissant les teneurs correspondantes des aliments, on calcule les coefficients d'utilisation digestive apparente de la matière sèche, de la matière organique et des protéines.

Les carcasses sommairement hachées sont lyophilisées, puis sur une partie aliquote homogénéisée par broyage, on détermine les teneurs en matière sèche, cendres et protéines. On calcule alors les quantités de protéines retenues au cours de la période expérimentale en admettant comme composition initiale de l'animal la valeur calculée à partir de l'équation de régression de la composition azotée des animaux témoins sur leur poids vif, selon la méthode proposée par Rérar et al. (r964). On détermine ainsi le coefficient d'utilisation pratique de l'azote, CUPN $=$ (azote retenu dans la carcasse/azote ingéré) $\times$ Ioo).

\section{C. - Expérience sur le Porcelet}

\section{Mode d'élevage des animaux.}

Les porcelets sevrés à I 2 jours sont placés en batterie dans un local climatisé $\left(26^{\circ} \mathrm{C}\right.$, 60 p. Ioo d'humidité). L'aliment granulé $(2,5 \mathrm{~mm})$ leur est distribué deux fois par jour en quantité croissant plus ou moins selon le niveau de consommation relevé lors du repas précédent. Jusqu'à l'âge de $2 \mathrm{r}$ jours, ils reçoivent exclusivement un lait artificiel contenant $25 \mathrm{p}$. Ioo de protéines. Par la suite, un aliment de $2^{\mathrm{e}}$ âge, renfermant 20 p. roo de protéines, ${ }^{1}$ ) est introduit progressivement dans li ration en proportion similaire à celle de l'aliment de présevrage par rapport au lait, observée chez le porcelet sous sa mère (AUMAITRE et SALMON-LEGAGNEUR, I96I). La suppression du lait artificiel à l'âge de 35 jours équivaut donc au sevrage fonctionnel à 5 semaines. A l'âge de six semaines, les animaux sont placés en loges classiques et le contrôle de la croissance se poursuit jusqu'à l'âge: de 9 semaines.

\section{Régimes expérimentaux (tabl. 3).}

A la suite de l'expérience sur Rat, on a retenu pour les essais sur Porcelet les farines soluble: 80 et 9o. Deux expériences successives ont été réalisées I et 2 dans lesquelles seule la composition du

(1) Composition p, roo: tourteau de soja 44:20 p. Ioo; farine de hareng:6 p. Ioo; poudre de lait. écrémé 5 p. roo orge $27 \mathrm{p}$. 100; manioc $29,7 \mathrm{p}$. Ioo; sucre $5 \mathrm{p}$. I00; suif $3 \mathrm{p}$. I0o; minéraux-vitaminesantibiotiques 4 p. Ioo; oxyde de chrome 0,3 p. Ioo. 
lait artificiel varie par le remplacement de tout ou partie du lait écrémé. Pour cela, on ajoute à la farine soluble une maltodextrine obtenue par hydrolyse enzymatique de l'amidon de maïs ( $\left.{ }^{1}\right)$ et dont la tolérance a préalablement été montrée chez le jeune porcelet (AUMAITrE, I97r non publié).

TABI,EAU 3

Composition des laits artificiels; expériences 1 et 2 sur porcelets (p. Ioo)

\begin{tabular}{|c|c|c|c|c|c|c|c|c|c|}
\hline \multirow{2}{*}{ Laits artificiels } & \multicolumn{6}{|c|}{ Expérience 1} & \multicolumn{3}{|c|}{ Expérience 2} \\
\hline & Témoin & $90-33$ & $90-66$ & $90-100$ & $80-33$ & $80-66$ & $80-100$ & $\begin{array}{c}80-100 \\
15-A D\end{array}$ & $\begin{array}{l}80-100 \\
15-1 T\end{array}$ \\
\hline Numéro du lait & 11 & 12 & 13 & 14 & 15 & 16 & 21 & 22 & 23 \\
\hline $\begin{array}{c}\text { Poudre de lait réengraissée } \\
(38 \% \ldots \ldots \ldots \ldots \ldots \ldots\end{array}$ & 65.7 & 65.7 & 39,2 & $\ldots$ & 65.2 & 38.2 & - & - & $\rightarrow$ \\
\hline Poudre de lait écrémé .... & 30,0 & 7,5 & -30,2 & - & $\begin{array}{r}0 J, 2 \\
7,5\end{array}$ & - & - & $\overline{-}$ & 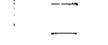 \\
\hline Farine soluble $90 \ldots \ldots \ldots$ & - & 9,5 & 19,0 & 28,5 & - & - & - & - & - \\
\hline $\begin{array}{l}\text { Farine soluble } 80 \ldots \ldots \ldots \ldots \\
\text { Malt odextrine engraissée }\end{array}$ & - & - & - & 一 & 10,0 & 20,0 & 30,0 & 30,0 & 30,0 \\
\hline$(22 \%) \ldots \ldots \ldots \ldots \ldots$ & - & - & - & 55,5 & - & - & $\mathbf{5 5 , 7}$ & - & 66,7 \\
\hline Maltodextrine pure $\ldots \ldots \ldots$ & 一 & 13,0 & 25,5 & - & 13,0 & 25,5 & & 50,7 & - \\
\hline Suif 1 er jus $\ldots \ldots \ldots \ldots \ldots$ & - & - & 12,0 & 12,0 & - & 12,0 & 10,0 & 15,0 & -- \\
\hline $\begin{array}{l}\text { Minćraux - vitamines - antibio- } \\
\text { tiques }\left({ }^{1}\right) \ldots \ldots \ldots \ldots \ldots\end{array}$ & $(t, 0)$ & 4,0 & 4,0 & 4,0 & 4,0 & $t_{4}, 0$ & $\{, 0$ & $\{, 0$ & $i, 0$ \\
\hline Oxyde de chrome....$\ldots$ & 0,3 & 0,3 & 0,3 & 0,3 & 0,3 & 0,3 & 0,3 & 0,3 & $1), 3$ \\
\hline Matière sèche (MS) $\ldots$. & 95,4 & 95,1 & 95,1 & 96,1 & 95,2 & 95,2 & 94,2 & 93,4 & 93,7 \\
\hline Protéines p. 100 de MS .... & 25,0 & 26,0 & 25,9 & 24,5 & 25,0 & 24,8 & 26,7 & 26,8 & 26,3 \\
\hline Énergie kcal/kg MS ....... & 5602 & 5709 & 5867 & 5839 & 5647 & 5824 & 5797 & 5284 & $j 35 t$ \\
\hline
\end{tabular}

(1) Composition (g/100 kg d'aliment) :

Minéraux : Phosphate bicalcique : 100 ; phosphate monocalcique : 100 ; sulfate de magnésium : 100 ; sulfate de fer : 50 ; sulfate de zinc : 20 ; sulfate de manganèse : 5 ; sulfate de cuivre : 2 ; sulfate de cobalt : 1 ; iodure de potassium : 0,2 .

Vitamines : choline $(25$ p. 100) $=240$; vitamine A $(50000 \mathrm{UL} / \mathrm{g}): 60$; vitamine D $(100 \mathrm{006} \mathrm{UI} / \mathrm{g})$ $=15 ;$ acide ascorbique $: 8 ;$ pyridoxine $: 1$; riboflavine $: 1$, thiamine $: 0,5$; pantothénate de calcium : 4,0; nicotinamide : 2,$0 ; \alpha$-tocophérol : 1,0 ; vitamine $B_{12}(100 \mathrm{mg} / \mathrm{kg})=50$; méthionine : 300 .

Antibiotiques : TO myxine (8 p. 1000 terramycine, 1 p. 1000 oléandomycine) $=1000$.

\section{Expérience 1 .}

On remplace dans les laits artificiels 33 et 66 p. I oo des protéines du lait écrémé soit par celles de la farine soluble 90 (lots 90-33 et 90-66), soit par celles de la farine soluble 80 (lots 80-33 et 8o-66). La suppression totale du lait de vache est réalisée dans l'un des laits artificiels par l'utilisation de farine soluble 90 (lot $90-100)$.

L'apport de lipides (suif I er jus), à un taux proche de celui du lait de truie ( $25 \mathrm{p}$. IOo), facilitant par ailleurs la granulation à froid de l'aliment témoin, est réalisé de trois façons différentes :

- grâce au lait écrémé réengraissé et homogénéisé avant séchage à 38 p. Ioo de matières grasses par rapport à la MS (tous laits artificiels, sauf le $1_{4}$ ),

(1) Sté des Produits du Maïs 92 I 40 Clamart. 
- par l'incorporation additionnelle de suif au cours du mélange à sec (laits artificiels I3, I 4 et I6),

- avec de la maltodextrine renfermant 22 p. roo de matières grasses incorporées par homogénéisation avant séchage (lait I 4 ).

\section{Expérience 2.}

Le lait de vache est remplacé en totalité par le mélange farine soluble 8o-maltodextrine. Le premier lait artificiel (2I) à $25 \mathrm{p}$. Ioo de matières grasses complète l'information apportée par l'expérience I. Les deux autres laits artificiels moins riches en matières grasses ( 15 p. IOo) doivent permettre de comparer les effets respectifs de l'addition directe de suif au lait artificiel (22, lot I5 AD) ou de son incorporation indirecte grâce à la maltodextrine enrichie en matière grasse (lait artificiel 23 , lot I $_{5} \mathrm{AT}$ ).

Les mélanges minéraux et vitaminiques sont communs à tous les laits artificiels des deux expériences. Tous les aliments, y compris l'aliment $2^{\mathrm{e}}$ âge commun, sont marqués à l'oxyde de chrome en vue des mesures de digestibilité.

\section{Schémas expérimentaux et interprétation statistique des résultats.}

\section{Expérience 1 .}

La mise en lot des animaux est exécutée selon le schéma des blocs incomplets équilibrés de type I (Cochrax et Cox, 1957). Au sein de chaque portée, on sélectionne six animaux que l'on répartit en trois couples équipondéraux logés dans trois cases contiguës de la batterie. On fait correspondre à chacun de ces trois couples une combinaison de 3 parmi les 6 traitements prévus. L'utilisation de 20 portées permet de réaliser toutes les combinaisons possibles des divers traitements 3 à 3 . De plus, deux portées contemporaines permettent de réaliser toujours une répétition des 6 traitements. Nous pouvons donc effectuer l'interprétation statistique des résultats comme dans le cas d'un schéma des blocs complets équilibrés, sans grand dommage pour la précision du test.

\section{Expérience 2.}

L'expérience n'incluant que trois traitements, en utilisant la même technique de mise en lot des animaux (3 couples par portée), on constitue des blocs complets. L'essai porte au total sur 6 répétitions.

\section{Mesures, analyses et expression des résultats.}

Les animaux sont pesés dès leur mise en batterie, puis chaque semaine entre la $2^{\mathrm{e}}$ et la $9^{\mathbf{e}}$ semaine d'âge; les quantités consommées sont mesurées par pesées des rations et des refus à chaque repas jusqu'à la $6^{\mathbf{e}}$ semaine d'âge. On peut donc tracer les courbes moyennes de poids et calculer individuellement les vitesses de croissance aux différentes périodes (1 $2-42$ et 12 -63 jours) ainsi que les quantités totales d'aliment consommé et les indices de consommation de 12 à 42 jours d'âge, pour chaque couple de porcelets.

Dès le quatrième jour de l'expérience, on collecte tous les matins, pour chaque couple de porcelets, des échantillons fécaux. Après séchage à $70^{\circ} \mathrm{C}$, on les regroupe par période de 7 jours et on détermine leur teneur en matière sèche, cendres, azote et oxyde de chrome. Connaissant la composition des aliments, on calcule les coefficients d'utilisation digestive apparente de la matière sèche, de la matière organique et des protéines à quatre périodes successives ( $15^{-2}$ I jours, 22-28 jours, $29-35$ jours et $36-4^{2}$ jours) selon la formule suivante :

$$
\operatorname{CUD}=\operatorname{roo}\left(\mathrm{I}-\frac{\mathrm{C}_{\mathrm{L}}+\mathrm{RC}_{\mathrm{S}}}{\mathrm{X}_{\mathrm{L}}+\mathrm{RX}_{\mathrm{S}}} \times \frac{\mathrm{X}_{\mathrm{F}}}{\mathrm{C}_{\mathrm{F}}}\right)
$$

ou $C_{L}:$ teneur en oxyde de chrome du lait artificiel,

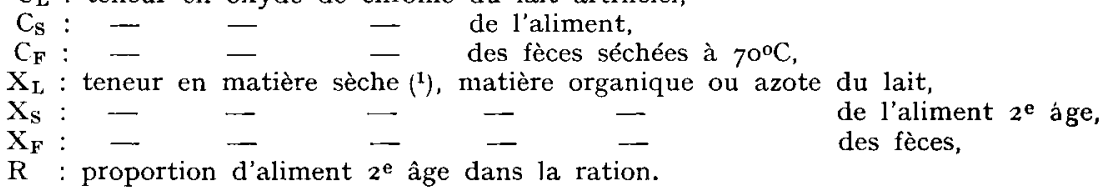

(1) Déduction faite de l'oxyde de chrome. 


\section{RÉSULTATS}

\section{I. - EXPÉRIENCE SUR RATS}

\section{A. - Croissance, consommation et indice de consommation (tab1. 4)}

I. Performances à 10 p .100 de protéines. Comparaison au témoin.

Avec les farines solubles de poisson blanc, le gain moyen journalier varie en raison inverse de la solubilité et de la concentration en protéines de la source azotée. La vitesse de croissance obtenue avec le régime témoin à base de farine de hareng

\section{TABLEAU 4}

Résultats de l'expérience sur le Rat

- vitesse de croissance

- consommation

- efficacité des protéines

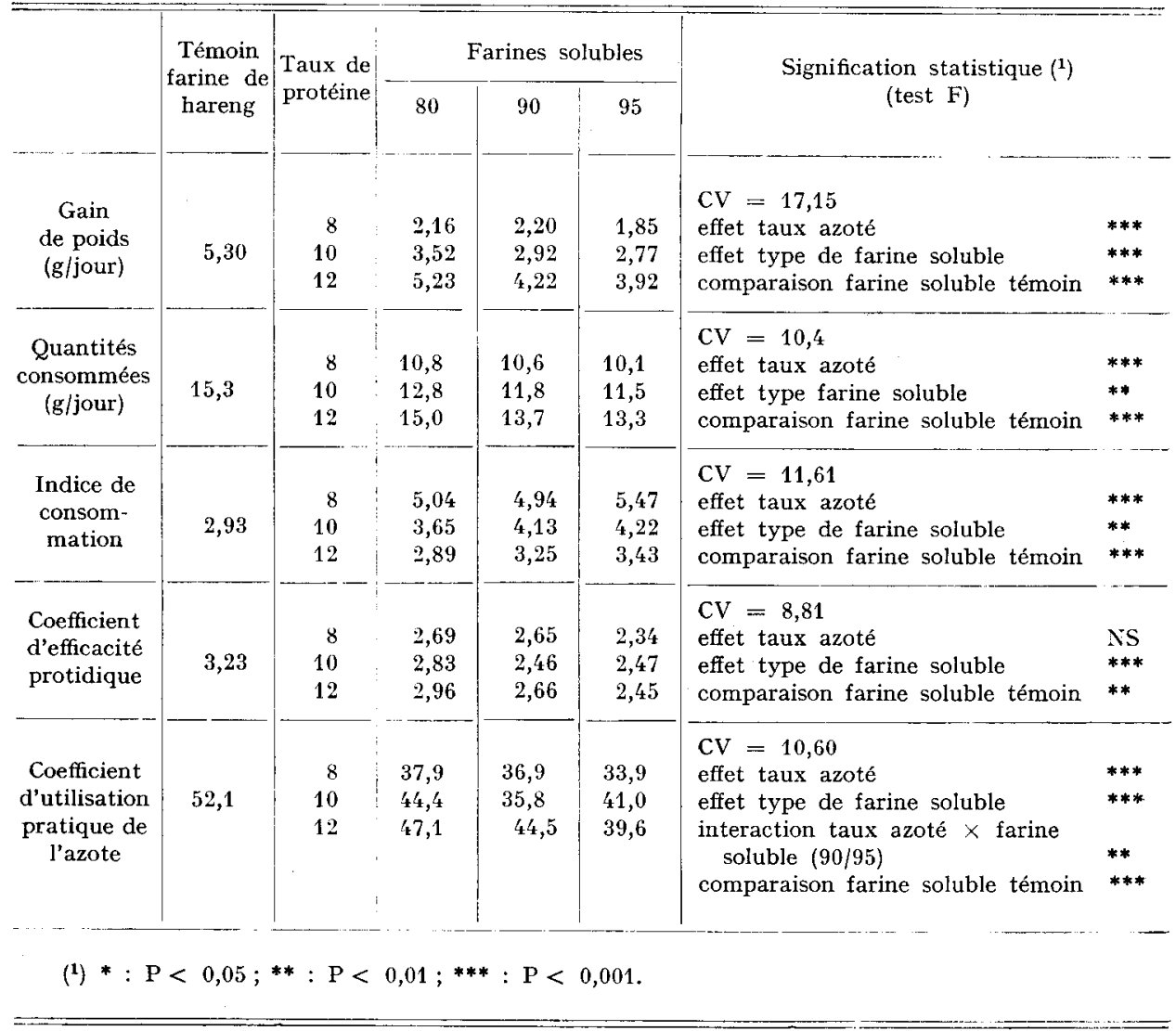


de Norvège est significativement plus élevée $(\mathrm{P}<0,00 \mathrm{r})$ qu'avec le meilleur régime expérimental (farine soluble 80 ). Les niveaux de consommation enregistrés varient de façon strictement parallèle à la vitesse de croissance. On relève surtout que la quantité d'aliment témoin consommé est nettement plus élevée $(\mathrm{P}<0$,oor $)$ que celle des aliments expérimentaux.

Les indices de consommation permettent d'attribuer sensiblement la même efficacité alimentaire au régime à base de farine soluble 90 et à celui qui contient la farine soluble 95. Par rapport à ces deux produits, on relève avec la farine soluble 80 une baisse de 15 p. Ioo de l'indice de consommation. Mais l'aliment témoin permet d'abaisser encore l'indice de consommation de 20 p. Ioo environ.

\section{Effet du taux de protéines.}

L'augmentation du taux de protéines entraîne une élévation significative de la vitesse de croissance et des quantités consommées, l'indice de consommation diminuant quelle que soit la farine soluble considérée $(\mathrm{P}<0, \mathrm{OI})$. Au taux de protéines le plus bas, c'est surtout l'infériorité de la farine soluble 95 qui est mise en évidence, alors qu'on ne peut différencier les farines solubles 80 et 9o. Au contraire à $\mathrm{I} 2 \mathrm{p}$. Ioo de protéines comme à Io $\mathrm{p}$. Ioo, les performances sont significativement meilleures pout la farine soluble 80 que pour les deux autres produits.

\section{B. - Efficacité protidique \\ et utilisation pratique de l'azote (tabl. 4)}

\section{Comparaison des farines dans les aliments contenant 10 p. 100 de protéines.}

Les coefficients d'efficacité protidique (CEP) des protéines des farines solubles 90 et 95 sont identiques et significativement inférieurs ( 44 p. Ioo) à celui de la protéine de farine soluble $80(\mathrm{P}<0,00 \mathrm{I})$. La supériorité de cette dernière, plus particulièrement sur la farine soluble go, est confirmée à l'examen des coefficients d'utilisation pratique de l'azote $(\mathrm{P}<\mathrm{0}, \mathrm{OOI})$. Cependant, les efficacités des protéines de farine de hareng pour la croissance et la rétention d'azote dépassent de I3 et I7 p. roo respectivement les résultats obtenus avec le meilleur produit soluble.

\section{Effet du taux de protéines.}

L'élévation du taux azoté de l'aliment ne modifie pas significativement le coefficient d'efficacité proditique alors que le coefficient d'utilisation pratique de l'azote augmente de 20 p. IOO $(\mathrm{P}<\mathrm{O}$,OOI $)$ environ lorsque le taux de protéines passe de 8 à $\mathrm{I} 2 \mathrm{p}$. Ioo. Cette variation est linéaire avec la farine soluble 80 qui conserve quel que soit le taux azoté sa supériorité sur les deux autres produits. En ce qui concerne les farines solubles 90 et 95 , les lois de variations du CUP de l'azote en fonction du taux de protéines de la ration semblent plus complexes.

$$
\text { C. - Digestibilité (tabl. 5) }
$$

\section{Comparaison des farines à 10 p. 100 de protéines dans l'aliment.}

La digestibilité de la matière sèche des régimes à base de farine de hareng est légèrement plus faible que celle des régimes à base de farine soluble 90 et $95(\mathrm{P}<0$,or $)$ la farine soluble 80 donnant un chiffre intermédiaire. Ces différences ne sont plus 
sensibles sur la digestibilité de la matière organique des régimes. La digestibilité de l'azote varie dans de plus larges proportions : ainsi, les protéines de farine de hareng de Norvège sont significativement moins digestibles que les protéines des farines solubles; la différence est de deux points avec les farines 90 et 95 , et un peu supérieure à un point avec la farine soluble 80 .

\section{TABLEAU 5}

Résultats de l'expérience

Digestibilité apparente des éléments de la ration sur le Rat

\begin{tabular}{|c|c|c|c|c|c|c|c|c|}
\hline \multirow{2}{*}{ Lots } & \multirow{2}{*}{\multicolumn{2}{|c|}{$\begin{array}{l}\text { Témoin } \\
\text { farine de Taux de } \\
\text { hareng protéine }\end{array}$}} & \multicolumn{3}{|c|}{ l'arines solubles } & \multirow{2}{*}{\multicolumn{3}{|c|}{$\begin{array}{c}\text { Signification statistique } \\
\text { (test } \mathrm{F})\end{array}$}} \\
\hline & & & 80 & 90 & 95 & & & \\
\hline $\begin{array}{l}\text { CUD } \\
\text { apparent } \\
\text { de la MS }\end{array}$ & 93,2 & $\begin{array}{r}8 \\
10 \\
12\end{array}$ & $\begin{array}{l}94,3 \\
93,5 \\
94,0\end{array}$ & $\begin{array}{l}94,1 \\
94,0 \\
94,6\end{array}$ & $\begin{array}{l}94,1 \\
94,2 \\
94,4\end{array}$ & $\begin{array}{l}\mathrm{CV}=0,66 \\
\text { effet taux de protéines } \\
\text { effet type de farine soluble } \\
\text { comparaison au témoin }\end{array}$ & $\begin{array}{l}\text { NS } \\
\text { NS } \\
\mathrm{P}<\end{array}$ & 0,001 \\
\hline $\begin{array}{l}\text { CUI } \\
\text { apparent } \\
\text { de la MO }\end{array}$ & 95,7 & $\begin{array}{r}8 \\
10 \\
12\end{array}$ & $\begin{array}{l}96,3 \\
95,6 \\
96,1\end{array}$ & $\begin{array}{l}95,9 \\
96,0 \\
96,2\end{array}$ & $\begin{array}{l}96,3 \\
96,1 \\
96,3\end{array}$ & $\begin{array}{l}\mathrm{CV}=0,38 \\
\text { effet taux de protéines } \\
\text { effet type de farine soluble } \\
\text { comparaison au témoin }\end{array}$ & $\begin{array}{l}\text { NS } \\
\text { NS } \\
\text { NS }\end{array}$ & \\
\hline $\begin{array}{l}\text { CUD } \\
\text { apparent } \\
\text { de l'azote }\end{array}$ & 89,1 & $\begin{array}{r}8 \\
10 \\
12\end{array}$ & $\begin{array}{l}88,9 \\
90,0 \\
91,7\end{array}$ & $\begin{array}{l}88,0 \\
91,4 \\
91,8\end{array}$ & $\begin{array}{l}90,1 \\
91,1 \\
92,1\end{array}$ & $\begin{array}{l}C V=1,29 \\
\text { effet taux de protéines } \\
\text { effet type de farine soluble } \\
1 \text { interaction taux azoté } \times \\
\text { farine soluble }(80-95 / 90) \\
\text { comparaison au témoin }\end{array}$ & $\begin{array}{l}\text { NS } \\
\text { NS } \\
\text { P }< \\
\mathrm{P}<\end{array}$ & $\begin{array}{l}0,05 \\
0,001\end{array}$ \\
\hline
\end{tabular}

\section{Effet du taux de protéines.}

Le taux de protéines n'influence ni la digestibilité de la matière sèche, ni celle de la matière organique. Par contre, le coefficient d'utilisation de l'azote augmente linéairement avec le taux azoté dans le cas des farines solubles 80 et 95 . Les différences entre les trois types de farine sont négligeables dans les rations au taux de I 2 p. IOo; au taux de 8 et Io p. IOO, les protéines de farine soluble 80 sont moins bien utilisées que celles de farine soluble $95(\mathrm{P}<0,05)$.

\section{II. - EXPÉRIENCE SUR PORCELETS}

\section{A. - Résultats zootechniques}

I. Période 12-21 jours (tab1. 6).

La croissance des animaux est de façon générale très lente pendant les premiers jours de l'expérience. Cependant, on discerne déjà des différences importantes entre les régimes lorsque les animaux atteignent 1'âge de 2 I jours. Dans 1'expérience $\mathbf{r}$, 
le gain de poids s'abaisse linéairement avec le remplacement du lait écrémé par la combinaison de farine soluble go et de maltodextrine. En revanche, l'effet obtenu est quadratique $(\mathrm{P}<\mathrm{o}, \mathrm{OOI})$ dans le cas de la farine soluble 80 et le gain de poids est significativement plus élevé qu'avec la farine soluble go. Par contre, l'analyse statistique ne permet pas de mettre en évidence des différences de niveau de consommation.

Dans l'expérience 2, à la même période, les animaux maintiennent mieux leur poids avec le lait artificiel 22 (matières grasses atomisées) mais les différences ne sont pas significatives, les quantités consommées étant identiques dans les trois lots.

TABLEAU 6

Résultats des expériences 1 et 2 :

gain de poids des porcelets et quantités de laits artificiels consommées entre 12 et 21 jours d'âge

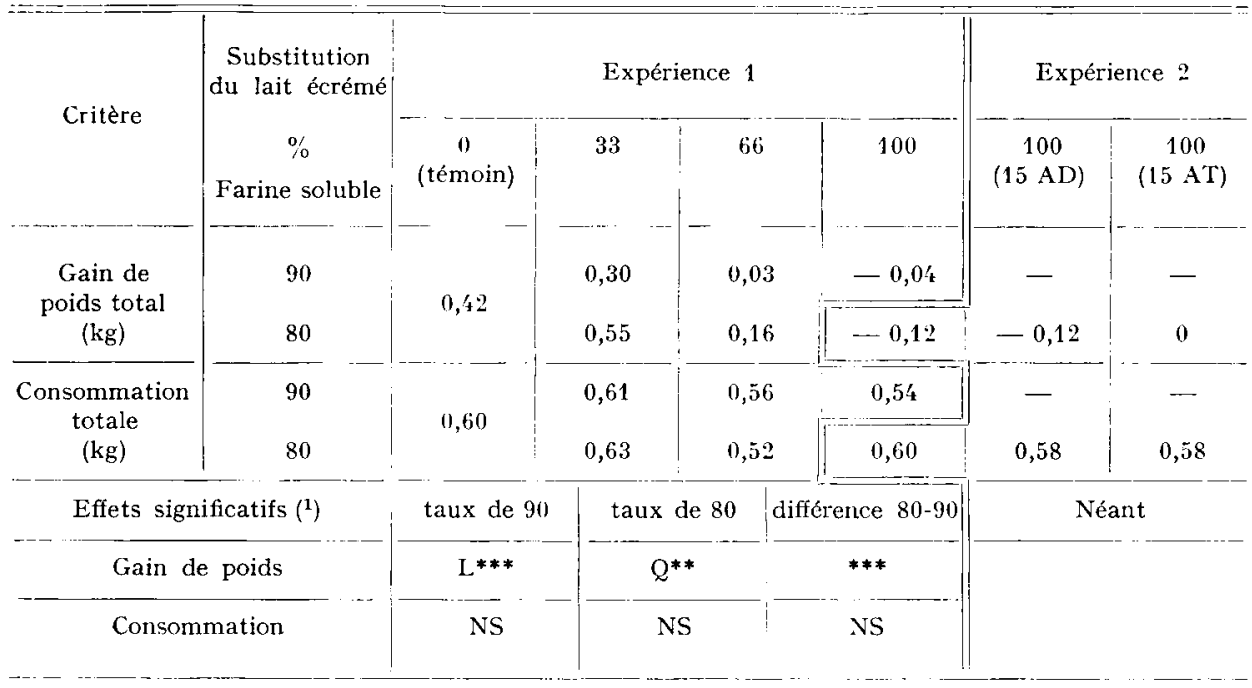

(1) $\mathrm{L}$ : effet linéaire ; $\mathrm{Q}$ : effet quadratique ; ${ }^{* *}: \mathrm{P}<0,01 ; * * *: \mathrm{P}<0,001$.

2. Période 12-42 jours (tab1. 7).

a) Gain de poids vif.

Les résultats sont pour l'expérience I strictement les mêmes que ceux déjà obtenus au cours de la phase I2-2I jours. Ainsi, l'influence favorable de l'introduction de farine soluble 80 à raison de 33 p. Ioo des protéines du lait artificiel est confirmée par la persistance d'un effet quadratique significatif. L'augmentation de la proportion de lait écrémé remplacé conduit à des performances plus faibles mais la supériorité de la farine soluble 80 est maintenue.

Lorsque ce même produit apporte la totalité des protéines des laits artificiels (expérience 2), il provoque une vitesse de croissance plus rapide que la farine soluble 80 dans le lot correspondant de l'expérience I (90-I00). Le taux et le mode d'introduction des matières grasses n'ont aucun effet significatif sur les performances de croissance. 


\section{TABLEAU 7}

Résultats des expériences 1 et 2 :

vitesse de croissance, consommation journalière et indice de consommation, entre 12 et 42 jours d'âge des porcelets

\begin{tabular}{|c|c|c|c|c|c|c|c|}
\hline \multirow{2}{*}{ Critère } & \multirow{2}{*}{$\begin{array}{c}\text { Substitution } \\
\text { du lait écrémé } \\
\qquad \% \\
\text { Farine soluble }\end{array}$} & \multicolumn{4}{|c|}{ Expérience 1} & \multicolumn{2}{|c|}{ Expérience 2} \\
\hline & & $\begin{array}{c}0 \\
\text { (témoin) }\end{array}$ & 33 & 66 & 100 & $\begin{array}{c}100 \\
(15 \mathrm{AD})\end{array}$ & $\begin{array}{c}100 \\
(15 \mathrm{AT})\end{array}$ \\
\hline \multirow{2}{*}{$\begin{array}{l}\text { Gain moyen } \\
\text { quotidien } \\
\text { (g/jour) }\end{array}$} & 90 & \multirow{2}{*}{191} & 163 & 126 & 92 & - & - \\
\hline & 80 & & 198 & 157 & 121 & 118 & 126 \\
\hline \multirow{2}{*}{$\begin{array}{l}\text { Consommation } \\
\text { (g/jour) }\end{array}$} & 90 & \multirow{2}{*}{227} & 212 & 195 & 160 & - & 一 \\
\hline & 80 & & 235 & 207 & 193 & 183 & 184 \\
\hline \multirow{2}{*}{$\begin{array}{l}\text { Indice de } \\
\text { consommation }\end{array}$} & 90 & \multirow{2}{*}{1,19} & 1,33 & 1,66 & $1,7 / t$ & - & - \\
\hline & 80 & & 1,20 & 1,36 & 1,61 & 1,57 & 1,46 \\
\hline \multicolumn{2}{|c|}{ Effets significatifs $\left({ }^{1}\right)$} & taux de 90 & \multicolumn{2}{|c|}{ taux de 80} & différence $80-90$ & \multicolumn{2}{|c|}{ Néant } \\
\hline \multicolumn{2}{|c|}{ Gain } & $\mathrm{L}^{* * *}$ & \multicolumn{2}{|c|}{$Q^{*}$} & $* * *$ & & \\
\hline \multicolumn{2}{|c|}{ Consommation } & $\mathrm{L}^{* * *}$ & \multicolumn{2}{|c|}{$(0,100)$} & $*$ & & \\
\hline \multicolumn{2}{|c|}{ Indice de consommation } & $L^{* * *}$ & \multicolumn{2}{|c|}{$\mathrm{L}^{*}$} & ** & & \\
\hline
\end{tabular}

(1) $\mathbf{L}$ : effet linéaire; $\mathrm{Q}$ : effet quadratique; $(0,10): \mathrm{P}<0,10 ; *: \mathrm{P}<0,05$; **: $\mathrm{P}<0,01$; $* * *: \mathrm{P}<-0,001$.

b) Quantités d'aliments consommées.

Dans l'expérience $I$, les quantités consommées décroissent de façon linéaire avec le taux de remplacement du lait par le mélange farine soluble go-maltodextrine. De la même façon que pour la vitesse de croissance, l'effet du taux de farine soluble 80 est quadratique. Ces différences de niveau de consommation ne se faisant sentir $q u$ 'à partir de $2 \mathrm{I}$ jours, nous avons étudié la variation des quantités consommées en fonction du poids des animaux au début de chaque semaine d'observation dans une analyse de covariance (fig. I). L'ajustement linéaire obtenu n'explique pas l'évolution des quantités consommées par le porcelet lorsque son poids augmente (effet période), mais rend très bien compte des différences de niveau de consommation entre lots d'animaux (effet traitement). Dans l'expérience 2, de la même façon que pour le gain de poids vif quotidien, les différences ne sont ni sensibles, ni significatives.

c) Indice de consommation.

Il augmente linéairement avec le taux de remplacement du lait écrémé par le mélange farine soluble 9o-maltodextrine. Par contre, lorsque la farine soluble 80 remplace $33 \mathrm{p}$. Ioo de protéines du lait écrémé, l'indice de consommation reste au 
même niveau que dans le lot témoin. Aux taux supérieurs de substitution, l'indice augmente, mais la supériorité de la farine soluble 80 reste hautement significative. Ces tendances sont similaires à celles relevées pour le gain de poids ou les quantités d'aliment consommées.

(A)

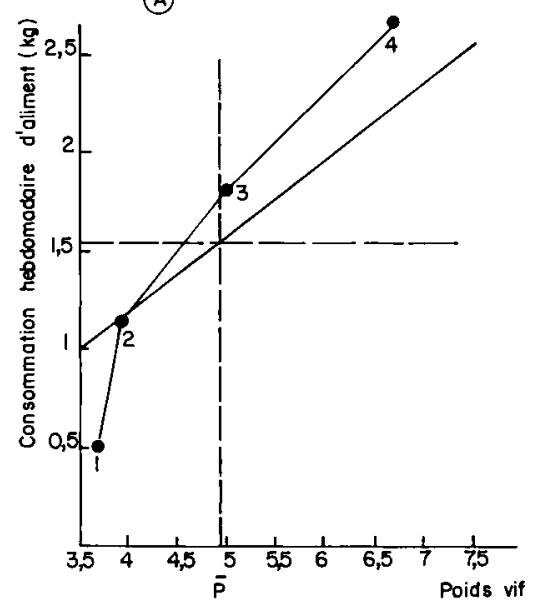

(B)

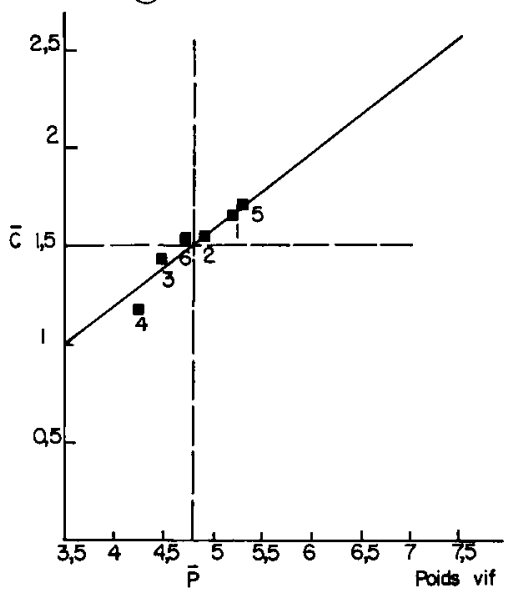

FIG. I. - Variation de la consommation hebdomadaive (c) d'aliment en fonction du poids au début de la semaine (ajustement linéaive donné par la variation résiduelle après l'analyse de covariance) $: \mathrm{C}=0,393 \mathrm{p}-0,367$

Signification statistique :
$\mathrm{A}:$ Effet semaine $=\mathrm{F}$ moyennes observées $=555,52$
F moyennes ajustées $=65,20$
$\mathrm{B}:$ Effet lot $=\mathrm{F}$ moyennes observées $=\mathrm{I}_{5}, 83$
$(\mathrm{P}<0$, OOI $)$
$(\mathrm{P}<0,001)$
$(\mathrm{P}<$ o,oor $)$
Non significatif

Dans l'expérience 2 , bien qu'aucun effet significatif ne soit mis en évidence, le lait artificiel à 5 p. Ioo de matières grasses atomisées semble mieux utilisé.

3. Période 12-63 jours (tabl. 8).

a) Évolution du poids moyen, vitesse de croissance.

Après 2I jours d'âge, les courbes de croissance témoignent d'une forte accélération du gain de poids des jeunes animaux avec l'âge (fig. 2). L'influence du régime qui apparaît très tôt se maintient jusqu'à l'âge de 63 jours malgré l'uniformisation de l'alimentation à partir de 35 jours. Sur l'ensemble de la période expérimentale, la vitesse de croissance s'avère très satisfaisante avec le régime témoin (3I $7 \mathrm{~g} / \mathrm{jour}$ ) et avec le régime qui comporte le remplacement de $33 \mathrm{p}$. Ioo du lait écrémé par la combinaison farine soluble 80-maltodextrine dans le lait artificiel (3I2 g/jour). Notons enfin que dans l'expérience 2 , le lot qui recevait le lait artificiel à I5 p. Ioo de matières grasses atomisées confirme à 9 semaines d'âge une supériorité de $8 \mathrm{p}$. Ioo, non significative, sur les deux autres.

b) Etat sanitaire, jours de diarrhée.

Le bilan de l'état sanitaire des animaux présenté au tableau 8 est relatif à la période $12-63$ jours. Toutefois, il convient de préciser que la fréquence d'apparition 
TABLEAU 8

Résultats des expériences 1 et 2 : vitesse de croissance et état sanitaire au cours de la période 12-63 jours d'âge des porcelets

\begin{tabular}{|c|c|c|c|c|c|c|c|}
\hline \multirow{2}{*}{ Critère } & \multirow{2}{*}{$\begin{array}{c}\text { Substitution } \\
\text { du lait écrémé } \\
\qquad \% \\
\text { Farine soluble }\end{array}$} & \multicolumn{4}{|c|}{ Expérience 1} & \multicolumn{2}{|c|}{ Expérience 2} \\
\hline & & $\begin{array}{c}0 \\
\text { (témoin) }\end{array}$ & 33 & 66 & 100 & $\begin{array}{c}100 \\
(15 \mathrm{AD})\end{array}$ & $\begin{array}{c}100 \\
(15 \mathrm{AT})\end{array}$ \\
\hline \multirow{2}{*}{$\begin{array}{l}\text { Gain moyen } \\
\text { quotidien } \\
\text { (g/jour) }\end{array}$} & 90 & \multirow{2}{*}{317} & 267 & 239 & 216 & \multirow{2}{*}{217} & \multirow{2}{*}{236} \\
\hline & 80 & & 312 & 277 & 219 & & \\
\hline $\begin{array}{l}\text { Jours de } \\
\text { diarrhée }\end{array}$ & & \multirow{2}{*}{1,7} & 3,0 & 2,3 & 1,8 & \multirow{2}{*}{1,0} & \multirow{2}{*}{0,9} \\
\hline par porcelet & 80 & & 1,8 & 1,8 & 1,4 & & \\
\hline \multicolumn{2}{|c|}{ Effets significatifs $\left({ }^{1}\right)$} & taux de 90 & \multicolumn{2}{|c|}{ taux de 80} & ence $80-90$ & \multicolumn{2}{|c|}{ Néant } \\
\hline \multicolumn{2}{|c|}{ Gain } & $\mathrm{L}^{* * *}$ & \multicolumn{2}{|c|}{$\mathrm{L}^{*}$} & $* *$ & & \\
\hline \multicolumn{2}{|c|}{ Jours de diarrhée } & $*(33)$ & \multicolumn{2}{|c|}{ NS } & $(* 33)$ & & \\
\hline
\end{tabular}

(1) $\mathrm{L}$ : effet linéaire ; * $: \mathrm{P}<0,05$; ** $: \mathrm{P}<0,01$; *** $: \mathrm{P}<0,001$.

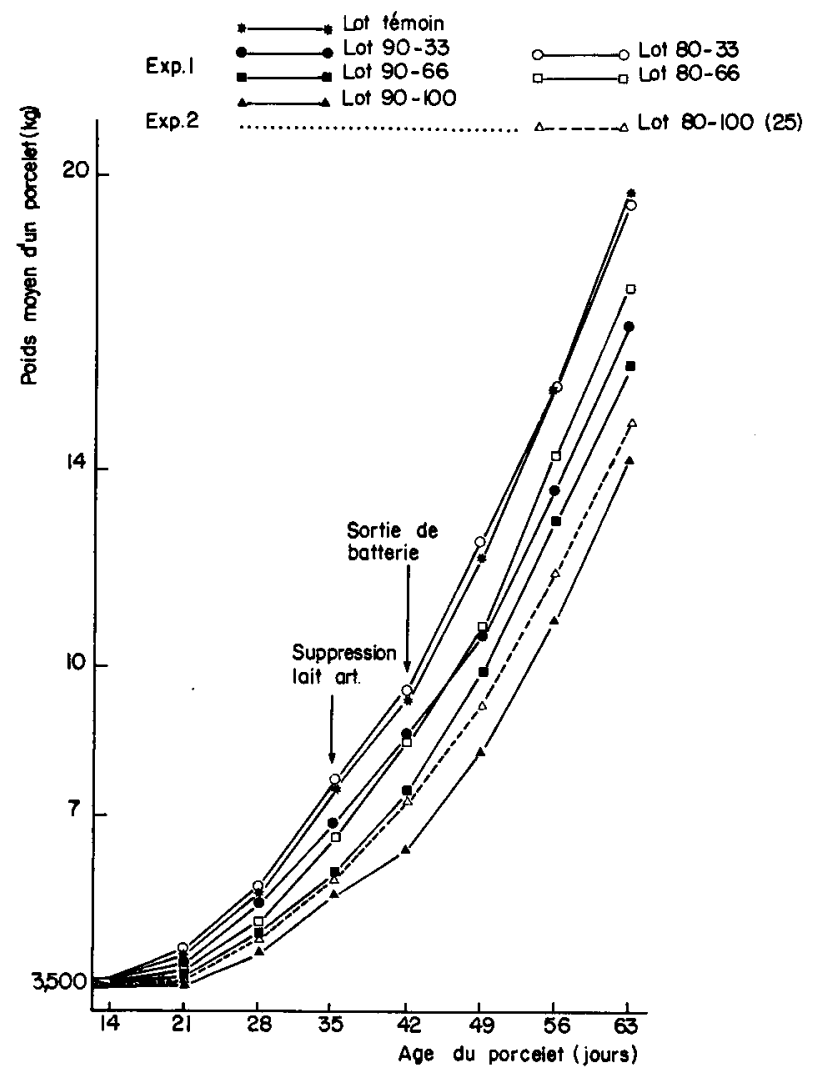

FIG. 2. - Évolution pondérale des porcelets au cours des expériences 1 et 2 
des diarrhées, faible dans l'expérience, est surtout importante lors de la période initiale (I2-2I jours). La combinaison farine soluble 9o-maltodextrine entraîne une dégradation de l'état sanitaire au plus faible taux de substitution du lait écrémé dans le lait artificiel, cet effet n'est plus ressenti lorsque la totalité du lait de vache est remplacée. En revanche, la combinaison farine soluble 80-maltodextrine maintient un bon état sanitaire quel que soit le taux auquel on l'introduit.

Dans l'expérience 2, l'état sanitaire était également très bon et aucune différence significative n'est à relever entre les lots.

\section{B. - Utilisation digestive des régimes}

La variance des données étant significativement plus élevée au cours de la période initiale (I2-2I jours), nous n'avons analysé les résultats qu'à partir de la seconde période ( 2 I- 28 jours).

I. Utilisation digestive apparente de la matière sèche et de la matière organique (fig. 3).

La composition des laits artificiels influence peu la digestibilité de la matière sèche ou de la matière organique des régimes, mais l'introduction progressive de
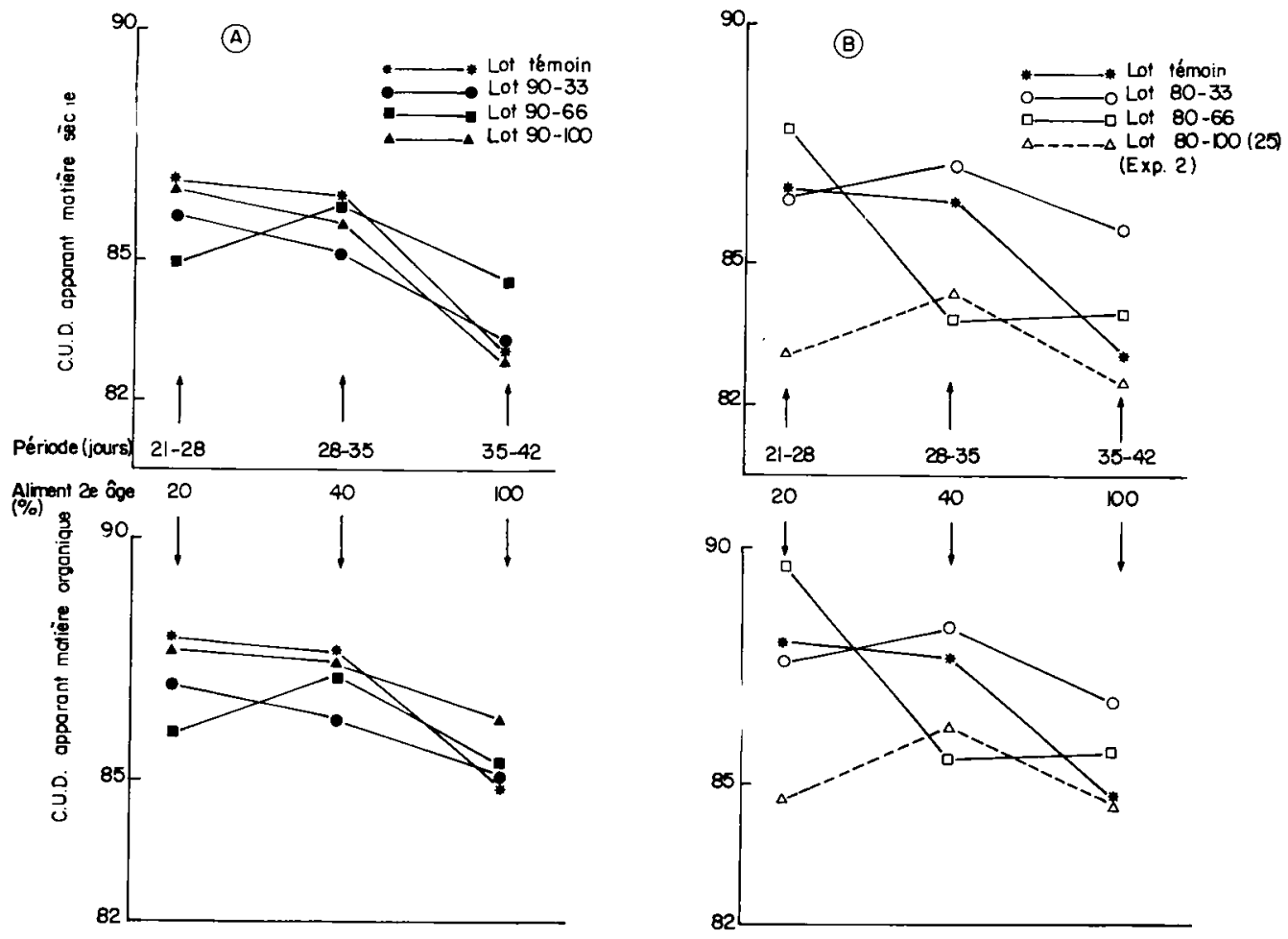

FIG. 3. - Évolution de l'utilisation digestive de la matière sèche et de la matière organique au cours des expériences 1 et 2 (lot 80-100 (25))

Signification statistique :

A : Néant

13 : Évolution significativement différente du lot 80-66 comparé aux lots témoins et $80-33(\mathrm{P}<0,05)$ 

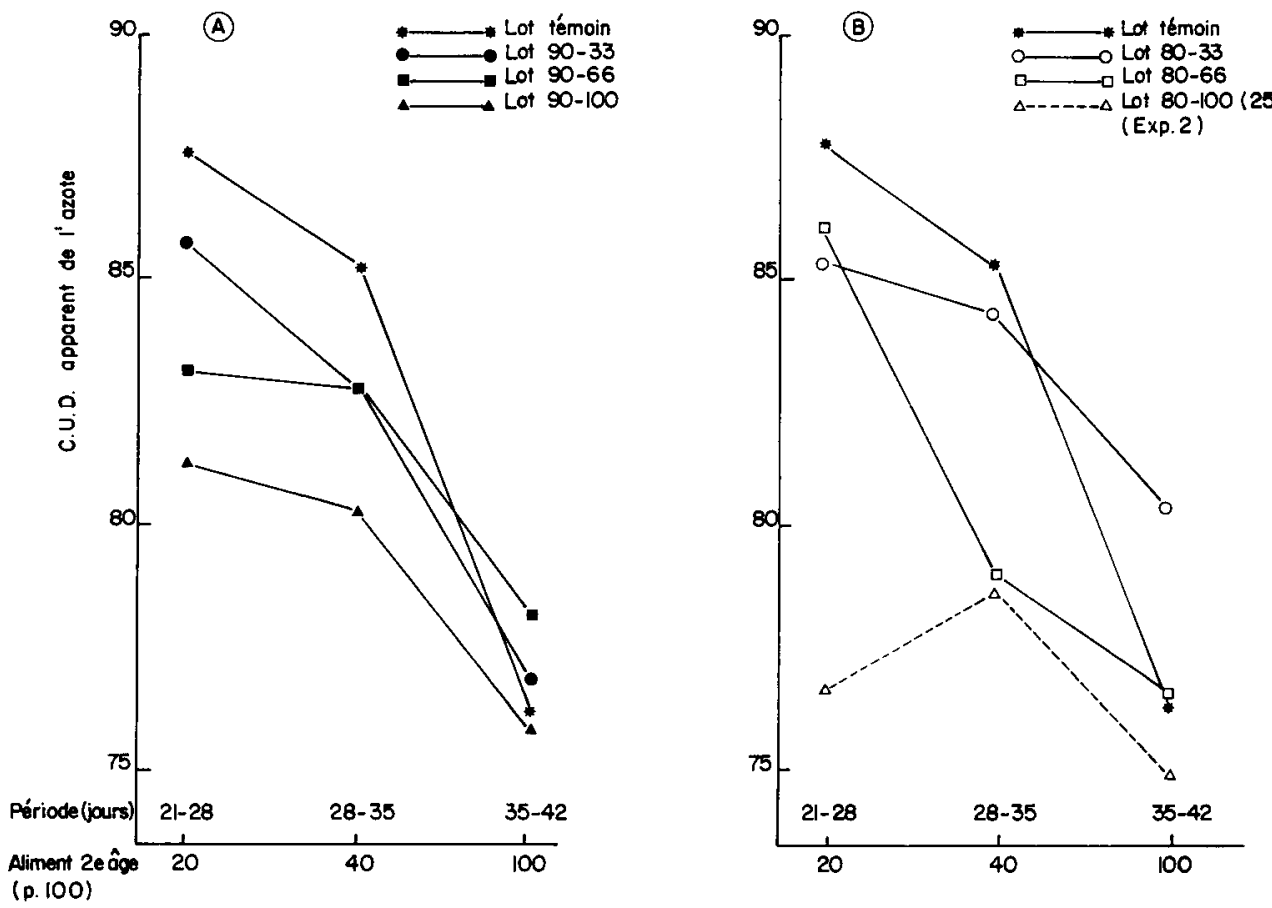

FIG. 4. - Evolution de l'utilisation digestive de l'azote au cours des expériences 1 et 2 (lot 80-100 (25))

Signification statistique :

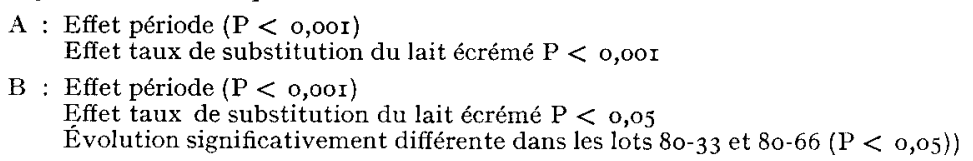

l'aliment $2^{e}$ âge dans les rations a des effets variables selon les lots d'animaux. Le coefficient d'utilisation digestive du régime témoin s'abaisse d'environ 4 points avec la suppression du lait artificiel $(\mathrm{P}<0,05)$; le remplacement du lait écrémé par le mélange farine soluble go-maltodextrine entraîne un effet analogue, plus limité, du fait que la digestibilité est initialement moins élevée. Au contraire, avec le remplacement par la combinaison farine soluble 80-maltodextrine au taux de 33 p. Ioo, la digestibilité se maintient à un niveau élevé (> 86 p. Ioo) même avec l'ingestion exclusive d'aliment $2^{\text {e }}$ âge (interaction non significative). Mais lorsque $66 \mathrm{p}$. Ioo du lait écrémé est remplacé par le même mélange, le coefficient d'utilisation digestive, initialement aussi élevé que dans le lot témoin, s'abaisse d'environ 4 points dès la période 28-35 jours (interaction significative $\mathrm{P}<0,05$ ).

Dans l'expérience 2, le remplacement total du lait écrémé dans le lait artificiel par le mélange farine soluble 80-maltodextrine entraîne une digestibilité sensiblement plus faible que dans le lot comparable (90-IO0) de l'expérience 2. Le taux et le mode d'introduction des matières grasses restent sans effet sur l'utilisation digestive apparente de la ration. 


\section{Utilisation digestive apparente de l'azote (fig. 4).}

Elle n'est pas influencée par le type de farine soluble utilisé tant que la ration renferme du lait écrémé à raison de 33 p. Ioo des protéines du lait artificiel. Cependant, lorsque la substitution du lait écrémé est totale, les résultats de l'expérience 2 tendent à montrer que les protéines de farine soluble 80 sont moins bien digérées que celles de la farine soluble 90 .

Lorsque les taux de remplacement du lait écrémé augmentent (o à 66 p. Ioo), on relève une diminution de la digestibilité des protéines de 5 à 6 points $(\mathrm{P}<0,00 \mathrm{I})$. Cependant, le résultat le plus net concerne la baisse de ro points de la digestibilité apparente de l'azote lorsqu'on augmente la proportion d'aliment $2^{\mathrm{e}}$ âge dans la ration. La substitution du mélange farine soluble 8o-maltodextrine au lait écrémé conduit à des observations analogues à celles effectuées pour la digestibilité de la matière organique. La baisse de digestibilité avec l'âge est nettement moins rapide dans le lot 80-33 que dans le lot témoin (interaction significative, $\mathrm{P}<0,05$ ) ; elle se produit dès la période $28-35$ jours dans le lot $80-66$, à partir d'une valeur initiale aussi élevée que dans les lots témoins et 80-33 (interaction significative $\mathrm{P}<0,05$ ).

La digestibilité des protéines ne semble modifiée ni par le taux, ni par le mode d'incorporation des lipides de la ration.

\section{DISCUSSION}

\section{Consommation et appétibilité des rations}

Le niveau de consommation d'un aliment complet dépend en premier lieu, chez le Rat, du niveau de satisfaction du besoin azoté qu'il procure, et les qualités organoleptiques de la ration ne prennent une réelle importance que lorsque l'animal a le choix entre deux ou plusieurs aliments (HENRY et RÉRAT, r965, I966). Ainsi s'explique dans notre essai l'élévation concomitante des quantités consommées et du taux de protéines. De la même façon, c'est probablement grâce à l'efficacité supérieure de ses protéines que l'aliment témoin est mieux consommé, plutôt que par un effet favorable de la farine de hareng sur l'appétibilité de la ration. Ces résultats ne permettent pas non plus de conclure que le traitement aux solvants nécessaire à la délipidation entraîne une modification quelconque de l'appétibilité de la farine soluble de poisson correspondante.

Chez le Porcelet, on insiste généralement sur la nécessité de distribuer avant et immédiatement après le sevrage un aliment très appétible (SALMON-LEGAGNEUR et FÉVRIER, I955). Dans nos conditions, les qualités organoleptiques des rations à base de farines solubles de poisson blanc semblent suffisantes puisque le niveau de consommation dépend essentiellement du poids vif atteint par 1'animal. Ce résultat est en accord avec ceux de SALMON-LEGAGNEUR et Aumaitre (I96I) qui observent une bonne appétibilité de la plupart des farines de poisson incorporées aux aliments de présevrage, à l'exception d'une farine de hareng de Norvège. De la même manière, chez le Veau, l'introduction de farine ou de concentré de protéines de poisson dans le lait artificiel ne semble pas abaisser le niveau de consommation jusqu'au taux de 35 à 40 p. Ioo des protéines du lait artificiel (HubER et Slade, I967 ; Toullec, Paruelie et Patureau-Mirand, I973). 
L'évolution de la consommation spontanée d'aliment en fonction du poids vif du porcelet est surtout marquée par le stress de sevrage qui limite considérablement le niveau de consommation au cours de la période d'une semaine environ nécessaire à l'adaptation du porcelet à un aliment granulé sec. Ce type d'évolution consécutif au sevrage précoce (A. R. C., I967) est probablement moins marqué avec l'utilisation d'un lait artificiel liquide auquel les porcelets s'adaptent très rapidement (BRAUDE et al., I970).

\section{Valeur alimentaire comparée de la farine de hareng et des farines solubles de poisson blanc}

La vitesse de croissance moyenne des rats témoins (régimes à I I p. Ioo de protéines) étant identique à celle des rats expérimentaux qui recevaient le régime farine soluble 80 à I 2 p. Ioo de protéines, le rapport des taux azotés permet d'estimer à environ $9 \mathrm{p}$. Ioo la supériorité des protéines de farines de hareng sur celles de la meilleure farine soluble de poisson blanc. Pour certains auteurs, les farines de poisson blanc présentent une meilleure valeur biologique que les protéines de poisson gras (Bender, MILIER et TunNaH, I953). Ces données ne sont pas confirmées par SCHILLER et SchulZ (I970) qui montrent que la variation inter-espèce de poisson n'est pas supérieure à la variation intra-espèce. Par ailleurs, les données rapportées par MrLIER (I970) montrent que les teneurs en acides aminés essentiels des protéines de poisson blanc de même type que ceux utilisés dans notre étude sont inférieures aux teneurs correspondantes des protéines de hareng rapportées ci-dessous :

\begin{tabular}{|c|c|c|c|}
\hline & Hareng & $\begin{array}{c}\text { Poisson } \\
\text { blanc }\end{array}$ & $\begin{array}{c}\text { Farine soluble } \\
\text { de poisson blanc }\end{array}$ \\
\hline & - & - & $\frac{(J 0100,19 / 2)}{-}$ \\
\hline Lysine . . . . . . . . . & 7,8 & 6,90 & 7,2 \\
\hline Méthionine + Cystine. . & 3,83 & 3,53 & 3,70 \\
\hline Tryptophane ........ & $\mathrm{I}, \mathrm{I} 5$ & 0,94 & - \\
\hline
\end{tabular}

De plus, cet auteur souligne que la disponibilité des acides aminés des farines de poisson blanc et notamment celle du tryptophane pourrait être plus faible chez le Poussin. Le traitement de solubilisation ne peut donc être tenu pour seul responsable de l'infériorité nutritionnelle des farines de poisson blanc étudiées et notamment de la farine soluble 80 qui n'est amputée d'aucune fraction de la matière première utilisée, à 1'exception de la partie osseuse des poissons.

\section{Comparaisons entre les types de farines solubles}

En revanche, il est important de considérer les différences de processus technologiques de fabrication pour expliquer les écarts des valeurs alimentaires des farines solubles étudiées.

L'utilisation de solvants (isopropanol) très courant dans la fabrication des concentrés de protéines de poisson, ne provoque pas d'effet dépressif spécifique de la croissance du Rat (MAKdani, 1969 ; MAKDaNi, Huber et BERGEN, I97I). L'infério- 
rité de la farine soluble 95 est donc plus probablement une conséquence de l'élimination de la fraction azotée insoluble. L'hypothèse se confirme lorsqu'on compare les farines solubles 80 et go qui sont classées dans le même ordre par le Rat et le Porcelet. En fait, la centrifugation qui permet de sélectionner les protéines les plus solubles de 1'hydrolysat a pour autre conséquence d'augmenter l'importance relative de la fraction que l'on désigne généralement par l'appellation " solubles de poisson ", pauvres en acides aminés indispensables et mal utilisée par les animaux (FÉVRIER et al., I954). De plus, au cours de l'hydrolyse, certains acides aminés indispensables sont libérés très lentement dans la fraction soluble. C'est particulièrement le cas du tryptophane (SRIPATHy et al., I963) qui pourrait être le facteur limitant des protéines d'hydrolysat de poisson. La teneur en tryptophane de la farine soluble go serait effectivement faible $(0,55 \mathrm{~g} / \mathrm{I} 6 \mathrm{~g}$ d'azote)selon une analyse récente (PION, I974). A ce jour, nous avons pu vérifier que la fraction insoluble qui lui est soustraite contient une protéine d'excellente qualité pour la croissance du rat.

\section{Effet de la solubilité des protéines de poisson sur leur digestibilité}

Chez le Rat, la digestibilité apparente des protéines augmente avec le taux de solubilité des farines étudiées. L'utilisation de trois taux de protéines pour l'étude des farines solubles autorise le calcul de leur digestibilité réelle que nous avons effectué selon la méthode de WIESEMÜLLER et POPPE (I969). Les résultats concernant les farines solubles 80 et 95 tendent à montrer que la solubilisation des protéines entraînerait une économie d'azote d'origine endogène, qui peut expliquer l'augmentation de la digestibilité apparente.

Chez le Porcelet, les coefficients de digestibilité obtenus avec la farine soluble go sont sensiblement supérieurs à ceux obtenus par d'autres auteurs avec des animaux du même âge recevant des farines (Combs et al., I963; KASPAR, I966) ou divers concentrés de protéines de poisson (BAYLEY et HOLMES, I973). La prédigestion enzymatique faciliterait l'étape de solubilisation pepsique des protéines chez un animal dont les sécrétions gastriques sont peu actives (BRAUDE et al., I958 ; WALKER, I959; HARTMAN et al., I96I), et permettrait de pallier la faiblesse des activités pancréatiques (PEKas, 'Thompson et Hays, ig66).

La baisse de digestibilité apparente de l'azote consécutive à l'introduction progressive de l'aliment $2^{\mathrm{e}}$ âge dans le régime s'explique en partie par la diminution progressive du taux de protéine de la matière sèche ingérée de 25 à $20 \mathrm{p}$. Ioo, et peut être consécutive à une augmentation relative de l'excrétion azotée d'origine endogène (Terroine, I936). Cependant, nous retrouvons pour 1'aliment $2^{\mathrm{e}}$ âge, distribué seul après 35 jours, une valeur de coefficient d'utilisation digestive apparente des protéines identique à celle trouvée au même âge chez des animaux tout récemment sevrés (Aumaitre, I969). Autrement dit, tout se passe comme si les laits artificiels utilisés ne favorisaient pas plus l'adaptation de l'animal à la digestion des protéines complexes que lorsque celui-ci est allaité par sa mère en consommant un aliment de présevrage. L'exception à cette règle, relevée dans notre expérience (lot 80-33) est intéressante car elle permet de penser que certaines caractéristiques du lait artificiel peuvent favoriser le phénomène d'adaptation digestive. Ceci nous conduit à formuler quelques hypothèses. 
Ainsi le lait artificiel 80-33 comporte l'association d'une source de protéine relativement peu digestible à l'état pur, la farine soluble 8o, et d'une quantité importante de lait de vache. Or, la présence de ce dernier semble favoriser la digestibilité de la protéine de poisson même lorsqu'elle représente une part plus importante de la fraction azotée du lait artificiel (8o-66). Ce résultat peut être la conséquence d'une interaction favorable des protéines et du lactose déjà observée dans le cas du soja par SEWELL et WEST (I965). Un résultat analogue est rapporté par BAYLEY et HOL,MES (1973) avec l'association de lactosérum à un concentré de protéines de poisson non soluble. On sait également qu'en présence de lait de vache, les modalités du transit digestif sont considérablement modifiées chez le porcelet par suite de la formation dans l'estomac d'un coagulum dense à base de caséine (WHITE et al., I969; BRAUDE et al., I970). Hif, et al., (I969) montrent en particulier que la vidange gastrique des protéines et des lipides est, comme chez le veau (MA'THIEU, I968), relativement lente et étalée dans le temps, alors que les glucides sont rapidement évacués. L'introduction de protéines de poisson dans le lait artificiel modifie sans doute la densité du coagulum mais ne le supprime pas (SEVE et LAPLACE, I974) et le freinage du transit qui en résulte pourrait être favorable à la digestion des protéines complexes de même qu'à l'adaptation progressive des sécrétions enzymatiques à leur hydrolyse.

\section{État sanitaire des animaux}

La fréquence de l'apparition des diarrhées observée avec la farine soluble 90 augmente lorsque le rapport lactose/protéines solubles s'élève, lors de la substitution du lait écrémé. Ceci pourrait alors provenir d'un excès de solubilité du concentré car le phénomène n'est pas observé avec la farine soluble 80 . Cette interprétation ne s'appuie sur aucune donnée connue, mais ce résultat tend à confirmer que d'importantes interactions glucides-protéines peuvent se produire lors du transit digestif des laits artificiels chez le Porcelet.

\section{CONCLUSION}

Dans nos conditions expérimentales, le parallélisme des résultats obtenus chez le Porcelet et chez le Rat justifie l'utilisation de ce dernier pour le choix des constituants azotés à introduire dans les aliments d'allaitement artificiel du porcelet. Finalement le taux optimum de remplacement du lait écrémé par une combinaison à base de fatine soluble de poisson de type 80 peut être situé à $33 \mathrm{p}$. Ioo chez le por-

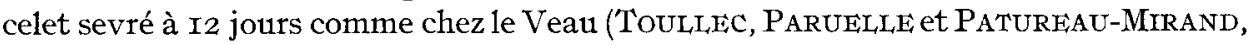
I973). Il ressort également de cette étude que la soustraction des composés insolubles du produit issu de l'hydrolyse se traduit par une dégradation de la valeur biologique des protéines de la farine obtentre, chez le Rat comme chez le Porcelet qui les digère bien mais les utilise mal. D'autres expériences seront nécessaires pour préciser aussi bien l'influence de la technologie de préparation, notamment celle du séchage de ces produits, sur leur valeur biologique, que la nature de leurs facteurs limitants.

Sur le plan plus général de la formulation des laits artificiels, les résultats obtenus 
mettent l'accent sur l'importance du problème de la digestibilité de la ration qui semble conditionnée à la fois par la structure physique de la protéine et la nature des glucides utilisés.

Reçu pour publication en juillet 1974.

\title{
REMERCIEMENTS
}

Ce travail a été entrepris grâce à l'aide de la Délégation Générale à la Recherche Scientifique et Technique (Contrat no 73-7-1055) à qui nous adressons nos plus vifs remerciements.

\author{
SUMMARY
}

\author{
FEEDING VALUE OF SOLUBLE WHITE FISH MEALS PREPARED \\ ACCORDING TO VARIOUS TECHNOLOGICAL PROCEDURES : \\ INCORPORATION INTO THE MILK REPLACERS \\ OF PIGLETS WEANED AT I2 DAYS
}

The feeding value of protein concentrates prepared by enzymatic hydrolysis of fresh fish was studied during the course of two experiments on 156 piglets weaned at $\mathrm{r} 2$ days. After a preliminary test on rats, two products (soluble meals 80 and 90 ) were retained for the experiment, a third one being climinated because of the deterioration of its feeding value consecutive to the defattening treatment. The soluble meals, combined with maltodextrin, replaced growing amounts (33, 66 and Ioo p. Ioo) of skim-milk in the pelleted milk substitutes offered to the piglets till the age of 35 days. The results showed that the elimination of the less soluble fraction of the hydrolysate, necessary for the production of meal go, led to a lowering of the nutritive value of the final product. Furthermore, the combination of the less soluble protein concentrate $(33 \mathrm{p}$. I00 of the dietary protein) with skim-milk had a favoutable effect on the maintenance of good growth performances in the piglets, satisfactory health and of an excellent apparent digestibility of the proteins. However, at the highest levels of skim-milk substitution, this digestibility of the dietary proteins decreased less rapidly with the most soluble product. This result, in accordance with the observations made on rats, tends to confirm the advantage of the enzymatic treatment of the fish.

It therefore seems that the technology used to obtain a product with maximum solubility leads to a decrease in the feeding value of the product, to be ascribed to the amino acid balance of the protein.

\section{RÉFÉRENCES BIBLIOGRAPHIQUES}

Agricultural Research council, 1967. Nutrient Requirements of farm livestock no 3 . Pigs Technical Reviews and Summaries. Agricultural Research Council, London.

Aumaitre A., I97I. Données non publiées.

Aumaitre A., I97x. Le développement des enzymes dans le tube digestif du jeune porcelet; importance pour le sevrage et signification nutritionnelle. Ann. Zootech., 20, 551-575.

Aumattre A., Salmon-Legagneur E., I96I. Influence de l'alimentation complémentaire sur la croissance du porcelet avant le sevrage. Ann. Zootech., 10, I27-I 40.

Aumaitre A., r969. Valeur alimentaire du manioc et de différentes céréales dans les régimes de sevrage précoce du Porcelet. Utilisation digestive de l'aliment et effet sur la croissance des animaux. Ann. Zootech, , 18, 385-398.

Barrick E. R., Vestal C. M., Shrewsbury C. L., I943. The nutritive value of certain fish meals as determined in tests with swine and rats. J. Agric. Res., 66, I25-I34. 
Bayley H. S., Holmes J. H. G., 1973. Evaluation of protein sources for early-weaned pigs. Proc. 9th Annual Nutrition Conference Feed Manufacturers, 80-98. University of Guelph and CFMA, Toronto, Ontario.

Bender A. E., Miller D. S., Tunnah E. J., 1953. The biological value of fish meals. Proc. Nutr. Soc., 12, ii.

Braude R., Dollar A. M., Mitchell K. G., Porter J. W. G., Walker D. M., I958. Proteolytic enzymes and the clotting of milk in the stomach of the young pigs. Proc. Nutr. Soc., 17, XLIX.

Braude R., Mitchell K. G., Newport M. J., Porter J. W. G., r97o. Artificial rearing of pigs. I. Effect of frequence and level of feeding on performance and digestion of milk proteins. Br. J. Nutr., 24, 50 I -5 I 6 .

Breirem K. I946. Norwegian herring meal. Norwegian feed for Norwegian animals. Landbrukshogsk. inst. Fôringslaere, Saertrykk $n^{\circ} 48,31$.

CARPENTER K. J., I95I. The relative value of animal and vegetable proteins for animals. Brit. J.Nutr., $5,243-249$.

Catron P. V., Nelson L. F., Ashton G. C., Maddock H. M., r953. Development of practical synthetic milk formulas for baby pigs. J. Anim. Sci., 12, 62-76.

Cochran W. G., Cox G. M., r957. Experimental designs, and edition, 6r i p. Ed. John Wiley and sons, New York.

Combs G. E., Osegueda F. L., Wallace H. D., Amerman C. S., ig63. Digestibility of rations containing different sources of supplementary protein by young pigs. J. anim. Sci., 22, 396-398.

Corring T., Aumaitre A., I971. Évolution du système enzymatique du pancréas et de l'intestin chez le porcelet allaité. Ann. Biol. anim. Bioch. Biophys., 11, 322-323.

Cunningham H. M., Brisson G. J., I957. The effect of proteolytic enzymes on the utilization of animal and plant proteins by newborn pigs and the response to predigested protein. J. Anim. Sci., 22, 396-398.

Dyrendahl S., Hellberg A., Ehlers T., Frederiksson Y., i958. Early weaning of piglets and the use of pelleted feeds for raising. Act. Agric. Scand, 8, 20-39.

Fevrier R., Jacquot R., Matet J., Pero R., i954. Influence du mode de préparation sur la valeur nutritive de trois farines de poisson. Le problème des eaux de presse et de la protéolyse. Ann. Zootech., 3, $223-246$.

Hartman P. A.. Hays V. W., Baker R. O., Neagle L. H., Catron D. V., ig6r. Digestive enzyme development in the young pig. J. Anim. Sci., 20, I I4-I23.

HENRY Y., RÉRAT A., I965. Ingestion spontanée d'éléments énergétiques en régimes mixtes ou séparés chez le Rat en croissance. Ann. Biol. anim. Bioch. Biophys., 5, 28 I-29o.

HeNR' Y., Rérat A., I966. Évolution de l'ingestion spontanée de principes énergétiques en fonction de la vitesse de croissance et de la protéinogenèse chez le Rat blanc. Cahiers A. E. C., 6, $239-26$ I. A. E. C., Commentry.

Hill K. J., Noakes D. E., Lowe R. A., I969. In Phillipson A. T., Physiology of digestion and metabolism in the ruminant, I66-I79. Oriel press LTD Newcastle upon Tyne.

Huber J. T., Slade L. M., 1967. Fish flour as a protein source in calf inilk replacers. J. Dairy Sci., 50, I $296-1300$.

JUNG J., 1972. Résultats non publiés.

Kaspar F., I966. Digestibility and utilization of nitrogenous substances of dried separated milk, fish meal, meat-bone meal and of blood flocules by piglets of an age from 14 to 56 days (Tchèque). Vedecke Pràce vyzhumného ùstavu pro chov prasat v kostelec nad orlici, I 967,2 , I 21 - I 27.

Laksesvela B., r961. Graded levels of herring meal to bacon pigs, effect on growth rate, feed efficiency and bacon quality. J. Agric. Sci., 56, 307-3I 5 .

Makdani D. D., I969. Nutritive value of fish protein concentrate. Ph. D. Thesis, Michigan State University, East Lansing.

Makdani D. D.,Huber J.T.,BerGeN W.G.,I97r. Effect of histidineand methionine supplementation on the nutritional quality of commercially prepared fish protein concentrate in rat diets. J. Nutr., 101, 367-375.

MathieU C. M., 1968. Étude de la vidange stomacale du lait entier chez le veau préruminant. Ann. Biol. anim. Bioch. Biophys., 8, 581-583.

Miller E. L., i970. Available amino-acid content of fish meals. F. A. O. Fisheries Circular, 120, 55.

N. R. C. I966. Nutrient requirements of laboratory animals, $n^{\mathbf{0}}$ ro p. $95,3^{\mathbf{e}}$ éd. National academy of Sciences. I'ashington D. C.

Pekas J.C., Thompson A. M., Hays V. W., I 966 . Characteristics of the exocrine pancreatic secretion of the young pig. J. Anim. Sci., 25, х13-12r.

Pion R., Fauconneau G., 1966. Les acides aminés des protéines alimentaires. Méthode de dosage et résultats obtenus. Cahier $A$. E. C., 6, I55-I75., A. E. C., Commentry.

Piox R., I974. Communication personnelle.

Pond W. G., Snyder W., Walker E. F. Jr., Stillings B. R., Sidwell V., ig7i. Comparative utilization of casein, fish protein concentrate and isolated soybean protein in liquid diets for growth of baby pigs. J. Anim. Sci., 33, 587-591. 
Rérat A., Fevrier C., Henry Y., Lougnon J., ig64. Evolution de la composition corporelle chez le Rat blanc en croissance. Ann. Biol. anim. Bioch. Biophys., 4, 35-47.

Salmon-Legagneur E., Fevrier R., i955. Les préférences alimentaires du Porcelet. I. Influence du mode de présentation des aliments : granulés ou farines. Ann. Zootech., 4, 215-218.

Salmon-Legagneur E., Aumaitre A., 1961. I.es préférences alimentaires du Porcelet. VI. Appétibilité des farines animales. Ann. Zootech., 10, 3I3-3I9.

Schiller K., Schulz E., I97o. Der liinfluss von Fischart und Herstellungsverfahren auf die Inhaltstoffe und Qualität von Fischmehlen. Iandreirtschaftliche Forschung, 23, IO9-I 23.

Seve B., Laplace J. P., I974. Influence de la substitution des protéines du lait par des protéines de poisson sur quelques caractéristiques du contenu gastrique chez le porcelet sevré à I 2 jours. Ann. Zootech., 24, 43-57.

Sewell R. F., West J. P., 1965. Some effects of lactose on protein utilization by the baby pig. $J$. Anim. Sci., 24, 239-24I.

Sripathy N.V., Kadkol S. B., Sen O.P., Swaminathan M., Lahiry N. L., I963. Iish hydrolysates. III. Influence of degree of hydrolysis on nutritive value. J. Food. Sci., 28, 365-369.

Terroine E. F., I936. Le métabolisme de l'azote. Physiologie des substancés protéiques. I. Aliments, digestion absorption enzymes digestives. $3^{8} 4$ p. Presses Univ. Fr., Paris.

Toullec R., Paruelle J. L., Patureau-Mirand P., i973. Fish protein concentrate utilization by the preruminant calf. European Nutrition Conference. Abstracts of short communications $n^{\circ} 35$. Cambridge I I-I 4 july.

VAN DER HEYDE., I969. Étude comparative de l'élevage des porcelets en batterie et de l'élevage traditionnel dans une exploitation mixte. Revue A gri, 22, I4I9-I428.

Walker D. M., 1959. The development of the digestive system of the young animal. I. Tissue weights, dry matter of tissues, total acidity and chloride content of stomach contents in the young pig. J.Agri. Sci., 52, 352-356.

White F., Wenham G., Sharman G. A. M., Jones A. S., Rattray 13. A. S., McDonald I., ig69. Stomach function in relation to a scour syndrome in the piglet. $B r . J . N u t r ., 23,847-858$.

Wiesemuller W., Poppe S., 1969. Die Bewertung der Proteine durch die Bestimmung der N. Bilanz. V. Die Bestimmung der wahren Verdaulichkeit bei N-Bilanzversuchen mit verschiedenen Proteingehalten in den Rationen. Arch. Tierernährung., 19, I49-156. 